GESTÃO PÚBLICA E GOVERNANÇA 


\title{
GOVERNANÇA NO SETOR PÚBLICO: UM ESTUDO NA ADMINISTRAÇÃO DIRETA ESTADUAL
}

\author{
GOVERNANCE IN THE PUBLIC SECTOR:
}

A STUDY IN DIRECT STATE ADMINISTRATION

Cícero Rodrigues Barbosa

Centro Universitário Alves Faria

Fernando de Abreu Faria

Data de submissão: 15 fev. 20 | 8. Data de aprovação:

07 jun. 20 8. Sistema de avaliação: Double blind review.

Universidade FUMEC / FACE. Prof. Dr. Henrique Cordeiro

Martins. Prof. Dr. Cid Gonçalves Filho.

Analista Bacen

\section{RESUMO}

A governança no setor público ainda é incipiente na administração pública do país, fato que indica a necessidade de novos estudos na área em função da importância e relevância do tema para uma gestão pública mais efetiva. $O$ objetivo central deste artigo consiste em analisar de que forma a adoção dos princípios de governança no setor público propostos no modelo do PSC/IFAC (200I), o Estudo 13, pode contribuir para uma gestão pública mais efetiva na administração direta do Estado de Goiás. No método foi utilizada uma abordagem qualitativa, de cunho descritivo. Quanto aos meios de investigação, utilizou-se a pesquisa documental, bibliográfica e o estudo de caso múltiplo na administração direta estadual. Os resultados indicaram que o modelo de governança praticado na administração direta do Estado de Goiás obteve alguns avanços nos últimos anos, mas ainda possui amplo espaço para evoluir por meio da adoção das melhores práticas indicadas pelo PSC/IFAC.

\section{PALAVRAS CHAVE}

Governança pública. Efetiva. Transparência. Integridade.Accountability. 


\section{ABSTRACT}

Governance in the public sector is still incipient in the country's public administration, a fact that indicates the need for new studies in the area due to the importance and relevance of the theme for a more effective public management. The main objective of this study is to analyze how the adoption of governance principles in the public sector proposed in the PSC I IFAC (200 I) model, Study 13, can contribute to a more effective public management in the direct administration of the State of Goiás. In the method a qualitative, descriptive approach was used.As for the means of investigation, we made use of the documentary, bibliographic research and the multiple case study in the state direct administration. The results indicated that the governance model practiced in the direct administration of the State of Goiás has made some progress in recent years, but still has ample room to develop through the adoption of the best practices indicated by the PSC / IFAC.

\section{KEYWORDS}

Public Governance. Effective. Transparency. Integrity. Accountability.

\section{INTRODUÇÃO}

Governança Corporativa pode ser entendida como a relação existente entre a gestão de uma organização empresarial e os stakeholders, ou seja, a forma como os gestores da empresa organizam suas relações com as partes interessadas no negócio. A governança corporativa surgiu como um instrumento relevante para a diminuição do conflito de interesses entre gestores e investidores nas corporações em meados da década de 80 nos EUA (RIBEIRO NETO e FAMÁ, 2003). Esse conflito, definido como conflito de agência por Jensen e Meckling (1976) é a divergência de interesses entre acionistas e gestores, em que um tenta tirar vantagens do outro de uma mesma situação.

Os conflitos de agência foram motivados pela falta de transparência e por gestões fraudulentas executadas pelos gestores dessas organizações no momento da tomada de decisões econômico-financeiras. A falta de ética e de transparência por parte dos gestores é responsável por falências de empresas pelo mundo. Por outro lado, dada a necessidade de financiamentos das atividades empresariais, as organizações que utilizam princípios e boas práticas de governança corporativa têm seus papéis mais valorizados no mercado internacional e possuem a preferência por parte dos investidores (RBC, 2008, p.42).

$\mathrm{Na}$ administração pública brasileira o termo governança foi um dos elementos fundamentais da reforma do Estado na década de 1990. Segundo Zonatto et al. (2010) existe governança em um Estado quando seu governo tem as condições financeiras e administrativas para transformar em realidade as decisões que toma. 
No setor público brasileiro não é incomum o fato de alguns agentes públicos utilizarem seus cargos em benefício próprio ou de terceiros, deixando em segundo plano os interesses da coletividade. De acordo com o Tribunal de Contas da União - TCÙ (20|4), a falta de governança no setor público prejudica a qualidade do serviço ofertado à população. Segundo estudos realizados desde 2012, o TCU informa que, na maioria das áreas, o dinheiro público não é bem aplicado, e o governo não tem indicadores claros sobre a eficiência do gasto público em função de falhas de planejamento e de gestão.

De acordo com Slomski (2007), o Brasil não possui indicadores de eficiência e, quando esses existem, não são claros e precisos. Assim, tem-se um longo caminho a percorrer para uma boa governança e utilização eficiente dos recursos. Para o TCU (20|4), a falta de uma boa governança não é exclusividade da União, está presente em todos os níveis da gestão pública nos Estados, Municípios e Distrito Federal. Como resultado, o Brasil tem dificuldade de crescimento porque não tem um bom planejamento das suas ações nem eficiência na fiscalização das mesmas. A eficiência do gasto público só será alcançada com a adoção de mecanismos de controle e monitoramento. A adoção de um modelo de boas práticas de governança, baseada em princípios pautados pela transparência da gestão, integridade e prestação de contas, pode contribuir para uma gestão efetiva (IFAC, 200I).

O IBGC (20I5) defende que, com algumas adaptações, é possível que os princípios de boa governança também sejam aplicáveis ao setor público. Esses princípios asseguram aos sócios a equidade, transparência, accountability (aqui indicando responsabilidade e prestação de contas) e conformidade (compliance) às normas jurídicas do país. Segundo a Federação Internacional de Contadores - IFAC (200I), a aplicação efetiva da governança corporativa ao setor público pode encorajar o uso eficiente dos recursos, a ampliação da transparência no uso dos recursos públicos e a responsabilização dos gestores, tornando assim as instituições públicas mais confiáveis e eficientes.

O Estado de Goiás como ente integrante da administração pública do país está sujeito às leis e regulamentos que regem o setor público, assim como também a exigência da transparência e de resultados positivos da gestão por parte dos seus contribuintes. A Lei Complementar n. ${ }^{\circ}$ IOI, de 4 de maio de 2000, chamada de Lei de Responsabilidade Fiscal- LRF, estabeleceu normas voltadas para a responsabilidade pela gestão fiscal e para uma maior cobrança e fiscalização em relação à transparência e prestação de contas.

A LRF contribui para a adoção das boas práticas de governança nos órgãos públicos do país pelos seus gestores, por propor o equilíbrio fiscal, limitar gastos com pessoal, limitar o endividamento público, dentre outros. Porém, a lei não traz consigo orientações sobre padrões de comportamentos dos gestores públicos referentes à liderança, códigos de conduta, processos, equilíbrio de poder e autoridade, gestão de risco, políticas de remuneração e medidas precisas de desempenho. Tais elementos estão presentes nas recomendações da International Federation of Accountants - IFAC (200I). Os princípios e recomendações do PSC/IFAC (200I) oferecem padrões norteadores das boas práticas de governança pública, pois, são utilizados na prática e fo- 
ram validados por pesquisas em vários países pelo mundo.

O Conselho Federal de Contabilidade - CFC (2016), considerando o processo de convergência das Normas Brasileiras de Contabilidade aos padrões internacionais e que, mediante acordo firmado com a IFAC que autorizou, no Brasil, o CFC como um dos tradutores de suas normas e publicações, outorgando os direitos de realizar tradução, publicação e distribuição das normas internacionais e demais pronunciamentos em formato eletrônico, aprovou a Estrutura Conceitual para Elaboração e Divulgação de Informação Contábil de Propósito Geral pelas Entidades do Setor Público, por meio da Norma Brasileira de Contabilidade (NBC), estrutura conceitual, em 23 de setembro de 2016 .

Portanto, seguindo-se os princípios e recomendações apontados no Estudo I3 do PSC/IFAC (200I), o propósito deste artigo é apresentar um estudo sobre a aderência e a contribuição desses princípios e recomendações para a gestão pública na administração direta do Estado de Goiás, e buscou responder a seguinte questão de pesquisa: Como a adoção dos princípios de Governança no setor público propostos no modelo do PSCIIFAC pode contribuir para uma gestão pública efetiva na administração direta do Estado de Goiás?

O trabalho está organizado em quatro partes além desta introdução. A primeira apresenta 0 conceito de governança no setor público, as dimensões e recomendações do Estudo 13 e as práticas atuais de governança no Estado de Goiás; na segunda parte é apresentado o método utilizado na pesquisa; a terceira refere-se à análise e discussão dos resultados; por fim, na quarta e última parte, são apresentadas as conclusões do estudo.

\section{Governança aplicada ao setor público}

O conceito de governança pública originou-se do termo governança corporativa. Enquanto a governança corporativa denota a forma como as organizações são administradas e governadas, a governança no setor público refere-se aos princípios de governança aplicados no setor público. Segundo Matias-Pereira (2010), a aplicação do conceito de governança corporativa é adequada no setor público, considerando a relevância da articulação e cooperação entre atores sociais e políticos, assim como o funcionamento consistente dos arranjos institucionais que coordenam e regulam transações socioeconômicas entre Estado, mercado e sociedade em um país.

A governança pública "pode ser entendida como o sistema que determina o equilíbrio de poder entre todos os envolvidos em uma organização - governantes, gestores, servidores, cidadãos - com vista a permitir que o bem comum prevaleça sobre os interesses de pessoas ou grupos" (MATIAS -PEREIRA, 20I0). De acordo com Slomski et al. (2008), a governança na gestão pública "é a maneira como o poder é exercido na administração dos recursos econômicos e sociais de um país, com o objetivo de seu desenvolvimento".

Para Kissler e Heidemann (2006) o significado original da governança pública contém um entendimento associado ao debate político-desenvolvimentista, no qual o termo é usado para referir-se a políticas de desenvolvimento que se orientam por determinados pressupostos sobre elementos estruturais como gestão, responsabilidades, transparência e legalidade do setor público, necessários ao desenvolvimento de todas as sociedades.

Diante dos diferentes conceitos e inter- 
pretações de governança no setor público, é possível perceber que todos pressupõem definições claras de responsabilidade e integridade dos gestores públicos, transparência dos atos administrativos, prestação de contas (accountability), grande importância dada às boas relações entre as partes interessadas (stakeholders), a administração dos recursos e finalmente a medição e entrega dos resultados.

É crescente a cobrança por parte da sociedade para que o setor público utilize os recursos financeiros de forma transparente e eficiente, com a prestação de contas e apresentação de resultados por meio da publicidade de relatórios que também demonstrem com clareza o desempenho da gestão. Dessa forma, a governança aplicada ao setor público visa garantir que os objetivos planejados sejam atingidos, por meio de uma estrutura organizacional bem projetada, controlada, supervisionada e com um processo de prestação de contas eficiente.

Em relação aos princípios de governança pública, a transparência diz respeito à divulgação de informações relevantes à população; a equidade implica a não concessão de privilégios por parte da administração pública (TCU, 20 I 4); accountability, que segundo ludícibus, Marion e Pereira (2003, p. I0), significa "responsabilidade do gestor profissional de prestar contas"; e compliance, que para Lodi (2000) é o cumprimento das leis, normas, regulamentos e determinações, ou seja, o mesmo que estar "em conformidade".

Segundo o Australian National Audit Office - ANAO (2002) e de acordo com Barret (2002) são seis os princípios fundamentais que as entidades devem seguir e aplicar para a governança pública. Como princípios relacionados às características pessoais dos agentes públicos estão liderança, integridade e comprometimento. Os princípios relacio- nados à forma estrutural como a entidade pública está organizada são transparência, responsabilização e integração.

\section{Princípios, dimensões e recomendações do PSC/IFAC}

A International Federation of Accountants - Federação Internacional de Contadores (IFAC) é uma organização não governamental fundada em 1977, em Munique, Alemanha, no $1 \mathrm{I}^{\circ}$ Congresso Mundial de Contadores. A organização tornou-se uma autoridade em governança financeira global, fato evidenciado pela Comissão Europeia de Normas de Auditoria (ISAs) por meio de publicações normativas sobre a prática de auditoria (LOFT, HUMPHREY e TURLEY, 2006).

O Public Sector Committiee (PSC) - Comitê do Setor Público - é um comitê permanente da International Federation of Accountants - Federação Internacional de Contadores (IFAC). Esse comitê da IFAC tem o objetivo de tratar de forma coordenada a nível mundial, as necessidades das pessoas envolvidas com o setor público em relação aos relatórios financeiros, contábeis e de auditoria. A propósito, o termo "setor público" faz referência às três esferas de governo (federal, estadual e municipal), assim como também às entidades governamentais sem fins lucrativos (IFAC, 2016).

Ao PSC tem sido dada a autoridade, em nome do Conselho, de emitir normas, diretrizes, estudos e trabalhos ocasionais em relatórios financeiros, contábeis e de auditoria no setor público. O PSC acredita que suas contribuições podem ser úteis para o desenvolvimento de orientações que poderão ser adaptadas às características regionais e nacionais em matéria de governança pública. $O$ Estudo I3, elaborado pelo PSC/IFAC em 200। 
centra-se em mecanismos de governança no setor público, especificamente sobre as responsabilidades dos gestores das entidades controladas pelo setor público. O PSC acredita que a publicação e posterior utilização deste estudo contribui para a boa governança e prestação de contas no setor público em todo o mundo (IFAC,200I).

O objetivo principal da maioria das entidades do setor público é prestar serviços à sociedade, em vez de obter lucros e gerar retorno financeiro aos investidores. Assim, a Estrutura Conceitual para Elaboração e Divulgação de Informação Contábil de Propósito Geral pelas Entidades do Setor Público (Estrutura Conceitual) estabelece os conceitos que devem ser aplicados no desenvolvimento das demais Normas Brasileiras de Contabilidade Aplicadas ao Setor Público (NBCs TSP) do Conselho Federal de Contabilidade (CFC) destinados às entidades do setor público. Além disso, tais conceitos são aplicáveis à elaboração e à divulgação formal dos Relatórios Contábeis de Propósito Geral das Entidades do Setor Público (RCPGs).
Para Marcelli (2013), o setor público apresenta grande diversidade na sua forma organizacional e na estrutura legislativa. Isso implica na necessidade de elaborar modelos de governança exclusivos e diferenciados para serem aplicados em setores e países diferentes, conforme suas especificidades, necessidades e características regionais. Ademais, os custos de implementação de uma recomendação de governança podem superar os benefícios da sua implementação. Por isso, adaptações podem ser necessárias de acordo com as características de cada entidade do setor público (IFAC, 200I).

O Estudo I3 - PSC/IFAC (200I, p. 19) utiliza os princípios fundamentais de governança corporativa elaborados no Cadbury Report em 1992, um relatório emitido pelo Comitê sobre os aspectos financeiros de Governança Corporativa, órgão público não departamental consultivo do governo do Reino Unido. O Cadbury Report definiu três princípios fundamentais da governança corporativa que são Transparência, Integridade e Accountability, conforme apresentado no Quadro I.

\section{QUADRO 1 - Princípios da Governança Aplicados ao Setor Público - PSC/IFAC}

\begin{tabular}{|c|l|}
\hline Princípios & \multicolumn{1}{c|}{ Definição } \\
\hline Transparência & $\begin{array}{l}\text { A transparência é necessária para garantir que os stakeholders possam ter plena confiança na } \\
\text { gestão das atividades e ações, principalmente na tomada de decisões por parte dos } \\
\text { administradores do setor público. Estar aberto por meio de consultas significativas com as } \\
\text { partes interessadas e dar publicidade a informações completas, precisas e claras, que levem a } \\
\text { medidas oportunas e eficazes, com a agilidade necessária. }\end{array}$ \\
\hline Integridade & $\begin{array}{l}\text { A integridade está relacionada com operações simples e também complexas. É baseada na } \\
\text { honestidade e objetividade, com elevados padrões de decoro e probidade na gestão dos } \\
\text { recursos públicos e de assuntos pertinentes à entidade. É dependente da eficácia do sistema de } \\
\text { controle e sobre os padrões relativos às normas de gestão de pessoal dentro da administração } \\
\text { pública. Ela reflete tanto na tomada de decisão da entidade quanto na qualidade de seus } \\
\text { relatórios financeiros e no desempenho da gestão. }\end{array}$ \\
\hline Accountabilityy & $\begin{array}{l}\text { A accountability é o processo pelo qual as entidades do setor público e os individuos dentro } \\
\text { delas são responsáveis por suas decisões e ações, incluindo a gestão dos recursos públicos e } \\
\text { todos os aspectos relacionados ao desempenho, que por sua vez serão submetidos ao escrutínio } \\
\text { externo adequado. Será alcançado por todas as partes, tendo uma compreensão clara de } \\
\text { responsabilidades e com papéis bem definidos através de uma estrutura robusta. Com efeito, a } \\
\text { responsabilidade é o dever de responder por uma responsabilidade que foi atribuida ao agente } \\
\text { público. }\end{array}$ \\
\hline
\end{tabular}

Fonte: Adaptado de IFAC (2001) 
De acordo com o próprio Estudo 13 do PSC/IFAC (200I), esses princípios fundamentais são refletidos em cada uma das "dimensões" da governança do setor público, que são apresentadas no Quadro 2.

As dimensões da governança aplicadas ao setor público propostas pelo PSC/IFAC (200I) funcionam como pilares de sustentação dos princípios fundamentais da governança pública. Para cada uma das dimensões, o PSC/IFAC (200I) descreve um conjunto de recomendações para a governança no setor público e, algumas dessas recomendações são subdivididas em elementos específicos de governança, conforme pode ser observado no Quadro 3. O foco dessas recomendações é centrado nas responsabilidades da gestão de cada órgão público e nas medidas que podem ser tomadas para que se tenha uma gestão eficiente e eficaz dentro da entidade.

\section{QUADRO 2 - Dimensões da governança no setor público do PSC/IFAC}

\begin{tabular}{|l|l|}
\hline \multicolumn{1}{|c|}{ Dimensão } & \multicolumn{1}{c|}{ Descrição } \\
\hline $\begin{array}{l}\text { Padrões de } \\
\text { Comportamento }\end{array}$ & $\begin{array}{l}\text { Como a gestão da organização exerce a liderança na determinação dos valores e padrões } \\
\text { da organização, que definem a cultura da organização e o comportamento de todos dentro } \\
\text { dela. }\end{array}$ \\
\hline $\begin{array}{l}\text { Estruturas e } \\
\text { Processos } \\
\text { Organizacionais }\end{array}$ & $\begin{array}{l}\text { Como a parte institucional da organização é nomeada e organizada, como as suas } \\
\text { responsabilidades são definidas, e a responsabilização é conduzida. }\end{array}$ \\
\hline Controle & $\begin{array}{l}\text { A rede de vários controles estabelecidos pela gestão da organização para apoiá-la na } \\
\text { consecução dos objetivos da entidade, a eficácia e a eficiência das operaços, a } \\
\text { confiabilidade dos relatórios internos e externos, e o cumprimento das normas, } \\
\text { regulamentos e politicas internas e externas à organização pública. }\end{array}$ \\
\hline $\begin{array}{l}\text { Relatórios } \\
\text { Externos }\end{array}$ & $\begin{array}{l}\text { Como a parte institucional da organização faz a demonstração da sua responsabilização } \\
\text { financeira pela gestão dos recursos públicos e o desempenho do seu uso. }\end{array}$ \\
\hline
\end{tabular}

Fonte: Adaptado de IFAC (2001)

QUADRO 3 - Recomendações de governança no setor público de acordo com o PSC/IFAC

\begin{tabular}{|c|c|c|}
\hline \multicolumn{3}{|c|}{ Padrões de Comportamento } \\
\hline \multicolumn{3}{|c|}{$\begin{array}{l}\text { Liderança } \\
\text { Códigos de Conduta } \\
\text { Probidade e propriedade } \\
\text { Objetividade, integridade e honestidade } \\
\text { - Relacionamento }\end{array}$} \\
\hline Estruturas e Processos Organizacionais & Controle & Relatórios Externos \\
\hline $\begin{array}{l}\text { Responsabilidade em prestar conta estatutária } \\
\text { Responsabilidade em prestar conta pelo } \\
\text { dinheiro público } \\
\text { Comunicação com as partes interessadas } \\
\text { Papéis e responsabilidades } \\
\text { - Equilibrio de poder e autoridade } \\
\text { O grupo de governo } \\
\text { - O presidente } \\
\text { - Membros do grupo de governo não executivo } \\
\text { - Administração executiva } \\
\text { - Politica de remuneração }\end{array}$ & $\begin{array}{l}>\text { Gestão de risco } \\
>\text { Auditoria interna } \\
>\text { Comitês de auditoria } \\
>\text { Controle interno } \\
>\text { Orçamento } \\
>\text { Administração } \\
\text { financeira } \\
>\text { Treinamento de } \\
\text { pessoal }\end{array}$ & $\begin{array}{l}>\text { Relatórios anuais } \\
>\text { Uso de normas } \\
\text { contábeis } \\
\text { apropriadas } \\
>\text { Medidas de } \\
\text { desempenho } \\
>\text { Auditoria externa }\end{array}$ \\
\hline
\end{tabular}

Fonte: IFAC (2001) 
Como pode ser observado, o foco das recomendações está centrado nas responsabilidades do corpo governante, ou seja, nos gestores do setor público. De acordo Oliveira e Pisa (20I5), encaminhando a discussão para a efetividade na área pública, concernente ao entendimento sobre a “boa governança no setor público”, o IFAC (200I) enfatiza que é função da governança garantir a supremacia do interesse público em todos os momentos.

\section{Governança e gestão na administração pública direta em Goiás}

Existe um interesse internacional em medir não apenas a qualidade dos serviços públicos, mas também melhorias na qualidade de vida da população nas dimensões como saúde, bem-estar social e meio ambiente.Além disso, alguns avanços recentes são encorajadores de melhorias dos processos de governança por meio de modelos específicos de governança e seus princípios basilares (BOVAIRD e LÖFFLER, 2003).

Para o CFC, devido à importância do orçamento público aprovado, as informações que possibilitam aos usuários compararem a execução orçamentária com o orçamento previsto facilitam a análise quanto ao desempenho das entidades do setor público. Tais informações instrumentalizam a prestação de contas e a responsabilização (accountability) e fornecem subsídios para o processo decisório relativo aos orçamentos dos exercícios subsequentes. A elaboração de demonstrativo que apresenta e compara a execução do orçamento com o orçamento previsto é o mecanismo normalmente utilizado para demonstrar a conformidade com os requisitos legais relativos às finanças públicas.

De acordo com o TCU (2014, p. I8), a governança no setor público é composta por "mecanismos de avaliação, direção e monitoramento; e às interações entre estruturas e processos, as quais determinam como os cidadãos e partes interessadas são ouvidos, como as decisões são tomadas e como o poder e as responsabilidades são exercidos." Goiás, como um Estado que compõe a Federação, precisa criar e colocar em prática as melhores práticas de governança, com objetivo de dirigir, monitorar, avaliar e prestar contas através de relatórios, visando obter uma gestão efetiva e a prestação de um serviço público de qualidade ao cidadão.

A Lei Complementar 131/2009 (Lei da Transparência), acrescentou alguns dispositivos à Lei Complementar 10 I/2000 (Lei de Responsabilidade Fiscal) que determinam a União, Estados, Distrito Federal e Municípios que disponibilizem informações pormenorizadas e em tempo real sobre a execução orçamentária e financeira em seus endereços eletrônicos na rede mundial de computadores. Em 20I I, a Lei Federal $n^{\circ}$ 12.527/20 I I (Lei de Acesso à Informação) reiterou a natureza pública das atividades desenvolvidas pelos órgãos de governo de todos os Poderes (Executivo, Legislativo e Judiciário) em todas as esferas de governo (União, Estados, Municípios e DF), determinando a obrigatoriedade de todo órgão ou entidade que recebe recursos públicos divulgar onde e como os recursos públicos são aplicados, além de explicitar a motivação para que esse dinheiro seja alocado em determinado local e de determinada forma.

Em 2013, o Estado de Goiás regulamentou no âmbito de sua competência os dispositivos que na Lei Federal se aplicavam exclusivamente à União de tal forma que não restassem dúvidas sobre o compro- 
misso do governo com a transparência de suas instituições. Para isso, foi editada a Lei Estadual $n^{\circ}$ 18.025/2013 que alcança os três Poderes, os Tribunais de Contas e - Ministério Público, bem como o Decreto $n^{\circ} 7.904 / 2013$ que trata exclusivamente das obrigações do Poder Executivo.

Nesse contexto, o portal Goiás Transparente (2016), regulamentado pelo Decreto $n^{\circ}$.6.965/2009 vem adaptando-se aos novos desafios impostos por essa realidade, consolidando-se como principal instrumento de promoção da transparência das ações do Poder Executivo do Estado de Goiás. No portal são divulgados os dados e informações relativas à execução orçamentária e financeira, os programas de governo dos órgãos e entidades da administração pública estadual direta e indireta, além de incentivar a participação do cidadão nos processos de planejamento, acompanhamento e avaliação das ações da gestão pública, o que contribui para a efetividade do controle social.

Para Campos, Paiva e Gomes (2013) o Estado de Goiás ainda está em fase de desenvolvimento em relação à transparência, sendo necessárias ainda algumas adaptações como melhorar a interatividade entre o cidadão e o site, além de tornar mais ágil a atualização de algumas informações.

O princípio da transparência fica evidente a partir do momento em que a gestão pública disponibiliza a todos os interessados, os procedimentos, informações relevantes e as decisões tomadas pelos gestores públicos. O princípio da integridade se faz presente na qualidade dos relatórios financeiros, na publicidade dos procedimentos licitatórios, no livre acesso do cidadão às informações da gestão de pessoal. $O$ princípio da accountability é alcançado quando os gestores divulgam informações sobre receitas, despesas e as metas alcançadas com a aplicação dos recursos públicos, execução orçamentária e financeira (empenho, liquidação e pagamentos) e com a medição do desempenho da gestão no Estado.

Tais princípios do PSC/IFAC (200 I) estão presentes no Sistema de Gestão Administrativa - SIGA, que é o instrumento de democratização do acesso às informações da Organização Administrativa do Poder Executivo do Estado de Goiás. Com visão panorâmica, o sistema retrata as competências legais, legislação básica, subordinação e organogramas de todos os órgãos e entidades, além de oferecer um histórico de toda a evolução desta organização administrativa (Goiás Transparente, 2016).

\section{MÉTODO}

Esta pesquisa é classificada quanto aos fins como descritiva, pois objetiva estudar as atuais práticas de governança aplicadas no setor público da administração direta do Estado de Goiás, considerando os princípios de governança pública - transparência, integridade e accountability - defendidos pelo modelo do PSC/IFAC (200I).

A abordagem é qualitativa, com a utilização de pesquisa documental e bibliográfica, e com a utilização da entrevista semiestruturada como principal técnica de coleta de dados na pesquisa de campo realizada em órgãos da administração direta do Estado de Goiás.

Por intermédio de estudo de caso múltiplo, com protocolo validado em um estudo piloto, o pesquisador atuou em quatro órgãos da administração direta do Estado. As validades de face e conteúdo do instrumento foram feitas anteriormente nos estudos que aplicaram o modelo PSC/IFAC em casos nacionais e também em outros países. 
Amostra, coleta, tratamento e análise de dados

A composição da amostra é não probabilística e como método não probabilístico foi utilizada a amostragem intencional.Além do Caso-Piloto realizado na Secretaria de Desenvolvimento Econômco (SED), foram selecionados quatro órgãos da administração direta do Estado: Secretaria de Estado de Educação, Cultura e Esporte (SEDUCE); Secretaria de Estado da Fazenda (SEFAZ); Secretaria de Estado da Casa Civil; e Controladoria Geral do Estado de Goiás (CGE). A escolha dos órgãos contemplados pela pesquisa é justificada pela importância estratégica dos mesmos dentro da gestão estadual e pelo acesso do pesquisador a esses órgãos.

Foi utilizada a entrevista semiestruturada com a adaptação do roteiro do Estudo 13 na versão em língua portuguesa elaborado pelo PSC/IFAC (200I), já validado por pesquisadores em estu- dos anteriormente realizados, com perguntas fechadas existentes nesse roteiro original, mas também com algumas questões abertas ao entrevistado, incluídas e adaptadas ao roteiro do estudo 13 do PSC/IFAC (200I) que tinham por objetivo facilitar a coleta das evidências pelo entrevistador.

As entrevistas realizadas pelo pesquisador, foram gravadas com o consentimento dos entrevistados e depois transcritas em software processador de texto. O tempo médio das entrevistas foi de 60 minutos, conforme pode ser observado no Quadro 4. Devido ao compromisso de confidencialidade assumido, os nomes dos entrevistados não são listados.

A análise e tratamento dos dados foi qualitativa. Para realizar a análise de dados, nesta pesquisa foi utilizada a análise temática. A descrição analítica funciona segundo procedimentos sistemáticos e objetivos de descrição do conteúdo das mensagens (BARDIN, 1979, p. 34).

QUADRO 4 - Entrevistas realizadas nos Órgão Públicos da Administração Direta

\begin{tabular}{|l|l|l|l|l|l|l|}
\hline $\begin{array}{l}\text { Entrevistado/ } \\
\text { Gênero }\end{array}$ & Órgão & Cargo Público & Formação & $\begin{array}{c}\text { Tempo } \\
\text { de } \\
\text { serviço } \\
\text { público }\end{array}$ & $\begin{array}{c}\text { Forma de } \\
\text { provimento } \\
\text { ao cargo }\end{array}$ & $\begin{array}{l}\text { Tempo da } \\
\text { entrevista }\end{array}$ \\
\hline $\begin{array}{l}\text { Caso Piloto/ } \\
\text { Masc. }\end{array}$ & SED & $\begin{array}{l}\text { Gerente de } \\
\text { Finanças }\end{array}$ & $\begin{array}{l}\text { Mestre em } \\
\text { Ciência } \\
\text { Politica }\end{array}$ & 9 anos & Efetivo & 60 min. \\
\hline $\begin{array}{l}\text { Caso 1/ } \\
\text { Masc. }\end{array}$ & SEDUCE & $\begin{array}{l}\text { Superintendente } \\
\text { de Gestão, } \\
\text { Planejamento e } \\
\text { Finanças }\end{array}$ & $\begin{array}{l}\text { Especialista } \\
\text { em Mercado } \\
\text { de Capitais }\end{array}$ & 12 anos & Efetivo & 93 min. \\
\hline $\begin{array}{l}\text { Caso 2/ } \\
\text { Masc. }\end{array}$ & SEFAZ & $\begin{array}{l}\text { Gerente de } \\
\text { Administração } \\
\text { Financeira }\end{array}$ & $\begin{array}{l}\text { Mestre em } \\
\text { Engenharia } \\
\text { de Produção }\end{array}$ & 12 anos & Efetivo & 45 min. \\
\hline $\begin{array}{l}\text { Caso 3/ } \\
\text { Fem. }\end{array}$ & CASA & $\begin{array}{l}\text { Superintendente } \\
\text { Executivo }\end{array}$ & $\begin{array}{l}\text { Especialista } \\
\text { em } \\
\text { Pedagogia }\end{array}$ & 48 anos & Comissionado & 55 min. \\
\hline $\begin{array}{l}\text { Caso 4/ } \\
\text { Masc. }\end{array}$ & CGE & $\begin{array}{l}\text { Gerente de } \\
\text { Monitoramento }\end{array}$ & $\begin{array}{l}\text { Especialista } \\
\text { em Processo } \\
\text { Civil }\end{array}$ & 9 anos & Efetivo & 65 min. \\
\hline
\end{tabular}

Fonte: Elaborado pelos Autores 


\section{Validade, confiabilidade e caso-piloto}

O protocolo do estudo de caso utilizado na pesquisa foi testado e validado por meio do estudo de caso piloto.As validades de face e de conteúdo, que seriam realizadas por meio das revisões feitas por profissionais da área de gestão, planejamento e finanças, não se fizeram necessárias, pois o roteiro do PSC/IFAC (200I) foi validado em estudos anteriores de outros pesquisadores. Como exemplo, pode-se citar as pesquisas mais recentes de Mello (2006), Silva (20I2), Silveira (20I3), Marcelli (20I3), TCU (20 I4) e Sales et al. (20 I5).

Dentre os aspectos que contribuíram para a validade externa estão a escolha de órgãos importantes estrategicamente dentro da estrutura de gestão do Estado; os entrevistados serem gestores de cargos do alto nível hierárquico (superintendentes e gerentes) que possuem experiência na gestão pública e principalmente, poder de decisão dentro do órgão público em que trabalham; a realização de um estudo de caso-piloto num órgão público da administração direta do Estado de Goiás, mais precisamente na Secretaria de Desenvolvimento Econômico-SED, para possíveis adequações do protocolo de estudo de caso.A utilização de múltiplas fontes de evidências, como fontes documentais, planilhas, conteúdos das entrevistas semiestruturadas e da observação direta efetuada pelo pesquisador, contribuíram também para aumentar a validade do construto, a partir da triangulação dessas diferentes fontes de dados (YIN, 200I).

Foi desenvolvido um banco de dados para armazenar todas as transcrições das entrevistas, documentos coletados e analisados, planilhas de prestação de contas, gráficos, anotações, enfim, todo material que foi produzido e utilizado na pesquisa. Essas informações coletadas e armazenadas no banco de dados, são importantes para a obtenção da confiabilidade do estudo de caso (RICHARDSON, 1999).

No estudo de caso piloto foi realizada entrevista semiestruturada com o gerente de finanças da SED, com a duração de aproximadamente uma hora, na sede do Órgão. Para complementar as informações obtidas por meio da entrevista e possibilitar a triangulação dos dados, foi utilizado como fonte de informações secundárias, os sites institucionais do órgão e do Goiás Transparente, documentos disponibilizados e conteúdos de e-mails institucionais. O sítio Goiás Transparente (2016) possui todas as informações necessárias à pesquisa, como relatórios de gestão, balanços e balancetes, gestão fiscal e financeira, receitas e despesas governamentais, convênios e repasses, informações sobre servidores, inclusive pagamento de proventos, manuais de procedimentos internos, organogramas, nomes dos gestores, que são disponibilizados ao público interessado, planejamento e orçamento.

A realização do estudo de caso-piloto possibilitou a validação do protocolo de estudo de caso. A quantidade de questões do roteiro do estudo I 3 do PSC/IFAC de pesquisa foi reduzido de 46 para 35 questões com o objetivo de otimizar o tempo de duração das entrevistas e fazer com que as mesmas se tornassem mais objetivas, dinâmicas e agradáveis aos entrevistados, sem perder a essência e o foco no objeto de pesquisa do roteiro.

\section{Análise e discussão dos resultados}

Cada caso foi analisado individualmente, baseado nas práticas de governança 
aplicadas ao setor público de acordo com as quatro dimensões propostas no modelo do PSC/IFAC, quais sejam: Padrões de Comportamento, Estrutura e Processos Organizacionais, Controle e Relatórios Externos, conforme representado na Figura I.

Assim, as fontes de dados - documentos oficiais disponibilizados nos websites dos órgãos e também aqueles disponibilizados pelos entrevistados, as entrevistas semiestruturadas com superintendentes e gerentes realizadas nas sedes de cada secretaria de Estado, especificamente no Caso I (SEDUCE), Caso 2 (SEFAZ), Caso 3 (Casa Civil) e Caso 4 (CGE) e também a observação direta pelo entrevistador - foram analisadas tendo como suporte as categorias e subcategorias do quadro-síntese de cada dimensão proposto no modelo do PSC/IFAC (200I) (vide Quadro 3).

Foi verificado que o desenho organizacional da administração de cada órgão pesquisado tem como características: a dife- renciação, a formalização e a centralização. De acordo com Bilhim (20l3), a diferenciação refere-se também à divisão do trabalho organizacional em departamentos e em camadas de níveis hierárquicos, o que pode ser verificado nos organogramas de cada secretaria de estado. A formalização refere-se à existência de regras e regulamentos para a execução das tarefas (HALL, 2004) e a centralização é uma característica em que se verifica uma maior retenção da autoridade pelos gestores e, consequentemente, um reduzido grau de delegação de autoridade (FARIA et al., 2006). Essa característica é evidente na estrutura administrativa do Estado de Goiás, já que o responsável máximo pelas decisões de cada órgão é o secretário de governo, seguido pelos superintendentes e gerentes, tudo definido por meio de legislações específicas.

Mesmo tendo sido pesquisados os mesmos aspectos em cada caso, que fazem parte de uma mesma estrutura organizacional, existiram variações nos resultados, já que

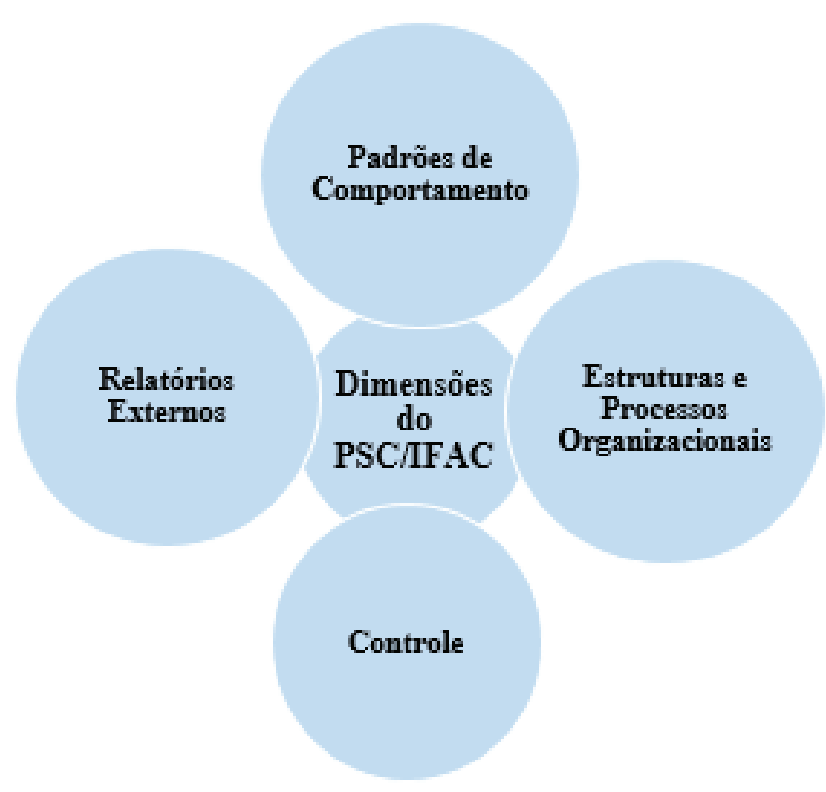

FIGURA 1 - Dimensões do Modelo de Governança do PSC/IFAC

Fonte: Elaborado pelos Autores 
cada órgão possui características e cultura organizacional específica, e sofrem influências de seus gestores apesar de terem o dever de seguir o princípio da legalidade dentro do serviço público prestado à sociedade. A seguir, o Quadro 5 evidencia a síntese dos resultados encontrados em cada caso pesquisado, de acordo com as dimensões e recomendações do modelo de governança pública proposta pelo PSC/ IFAC (200I).

De acordo com o estudo realizado nos quatro órgãos públicos pesquisados da administração direta do Estado de Goiás foi constatado que não são utilizados modelos próprios ou específicos de governança pública. Ficou evidente que esses órgãos públicos são administrados por meio de legislações nacionais como a Lei de responsabilidade fiscal (Lei no I0I/2000), normas de direito financeiro (Lei no 4.320/64), Lei de acesso a informação (Lei n॰ 12.527/20 I I), Lei das licitações (Lei n॰ 8.666/93), assim como também legislações estaduais, como o estatuto do servidor púbico (Lei n०10.460/88), decretos de execução orçamentária (Lei no 8356/2016) e financeira, leis orçamentárias (PPA, LDO, LOA), regimentos e instruções normativas internos, manuais, dentre outros.

\section{Considerações finais}

Para responder à questão de pesquisa proposta "Como a adoção dos princípios de Governança no setor público propostos no modelo do PSC/IFAC pode contribuir para uma gestão pública efetiva na administração direta do Estado de Goiás?", foram utilizadas as quatro dimensões do modelo do PSC/ IFAC (200I): padrões de comportamento, estruturas e processos organizacionais, controle e relatórios externos. Dessa for- ma, procurou-se verificar se o modelo de governança adotado nos quatro órgãos da administração direta do Estado de Goiás está de acordo com as recomendações propostas em cada dimensão do modelo proposto pelo PSC/IFAC. O estudo permitiu verificar quais princípios de governança do modelo do PSC/IFAC são adotados pela administração direta do Estado de Goiás.

De acordo com os resultados encontrados nos quatro casos, ficou evidente que o modelo de governança praticado na administração direta do Estado de Goiás pode ser melhorado, considerando-se os três princípios do modelo do PSC/IFAC, transparência, integridade e accountability. No que se refere ao princípio da transparência, é necessário fazer uma aproximação entre sociedade e Estado, principalmente em relação ao sítio Goiás Transparente. A população precisa conhecer esse instrumento e saber utilizar as suas ferramentas, reconhecendo a importância do mesmo como ferramenta de controle das ações governamentais e de prestação de contas da utilização dos recursos públicos. O Estado tem o papel de não apenas divulgar esse canal de comunicação, mas também de integrar a sociedade ao mesmo, incentivando a sua utilização por meio de uma linguagem mais clara e eficiente para o cidadão.

Com referência ao princípio da integridade, é preciso estabelecer um controle estratégico efetivo, no nível institucional, para que os gestores possam analisar se os objetivos estão sendo cumpridos, e também avaliar se o desempenho de cada membro da administração pública está de acordo com as metas preestabelecidas. É importante que se estabeleça um sistema de metas e resultados nos órgãos públicos de forma concomitante com uma política 


\section{QUADRO 5 - Síntese Comparativa dos Resultados: Dimensões e Recomendações do PSC/ IFAC na Administração Direta do Estado de Goiás}

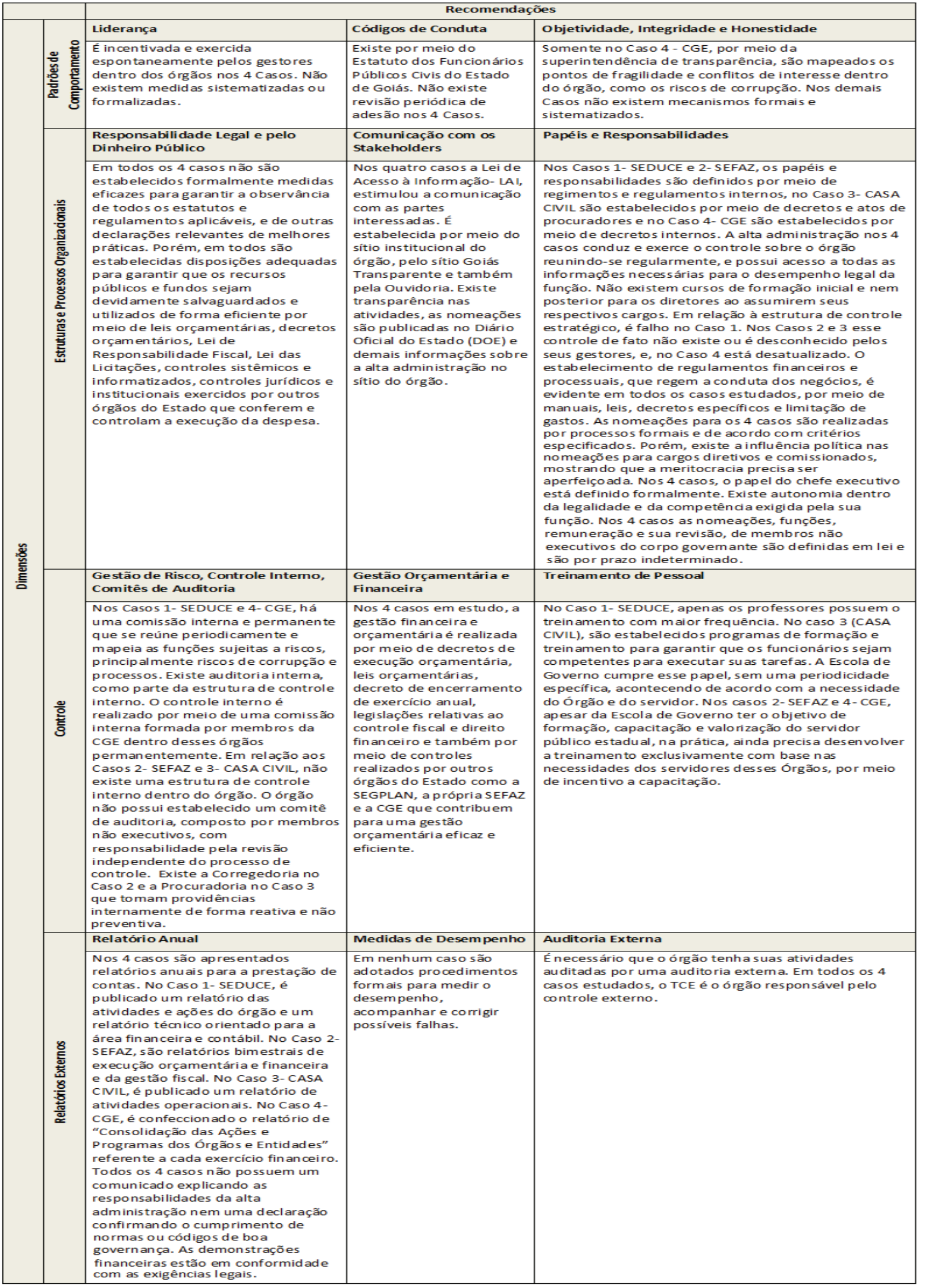

Fonte: Elaborado pelos Autores 
de incentivo para que as metas sejam cumpridas. $O$ servidor público precisa passar por cursos de aprimoramento de acordo com suas necessidades e a função que desempenha, para que possa prestar um serviço público mais eficiente à população.

Em termos de accountability, apesar do Estado de Goiás seguir a Lei Orgânica do TCE (20I I), que estabelece os prazos para a prestação de contas, é necessário estabelecer um mecanismo mais eficiente para a distribuição dos relatórios financeiros e contábeis em prazos mais curtos ou mesmo em tempo real por meio de sistemas apropriados para a própria avaliação do TCE. Se a prestação de contas for mais dinâmica e integrada entre os órgãos públicos e a corte de contas, haverá mais chances de se encontrar possíveis discrepâncias até mesmo antes do encerramento do exercício financeiro.

Esta pesquisa procurou contribuir com a administração pública do Estado de Goiás ao mostrar aos gestores públicos a realidade do modelo de governança pública adotado no Estado em comparação ao modelo proposto pelo PSC/IFAC (2001), instituição que possui credibilidade e é reconhecida no mundo. Acredita-se que por meio desta pesquisa, a administração pública direta do Estado de Goiás poderá, de acordo com suas necessidades, fazer adaptações em seu modelo de governança, adotando ainda mais, boas práticas de governança pública visando uma administração pública mais transparente, eficiente e efetiva em benefício do cidadão.

Dentre as limitações da pesquisa estão a sua aplicação apenas na administração direta do Estado de Goiás e a não participação da Secretaria de Gestão e Planejamento do Estado (SEGPLAN) em função da falta de disponibilidade por parte dos gestores. Para pesquisas futuras indicam-se três possibilidades não contempladas neste estudo: a aplicação da pesquisa em outros órgãos da administração direta para fins de comparação; aplicação do modelo do PSC/IFAC (200I) também em órgãos públicos estaduais da administração indireta, como as autarquias, empresas públicas e sociedades de economia mista; e, por fim, a elaboração de instrumentos para analisar as dimensões do PSC/IFAC de forma quantitativa para mensurar a existência de uma possível correlação entre a adoção das recomendações de cada dimensão do referido modelo e o índice de satisfação da população com a administração pública. 
ANAO,Australian National Audit Office. Applying principles and practice of corporate governance in budget agencies. 2002. Disponível em:< http:// www.anao.gov.au>. Acesso em: 24 mar. 2016.

Auditor General for Austrália. (2003). Disponível em:<http://www.anao.gov.au/ uploads/documents/>.Acesso em: 22 mar.20l6.

BARDIN, Laurence. Analise de conteúdo. Lisboa: Edições 70, 1979.

BARRET, P. Achieving Better Practice Corporate Governance in the Public Sector. AM Auditor General for Austrália. (2002). Disponível em: <http://www.anao. gov.au/uploads/documents/>. Acesso em: 22 mar.2016.

BILHIM, João. Teoria Organizacional: Estruturas e Pessoas ( $7^{\mathrm{a}}$ ed.), Lisboa: ISCSP, 2013.

BOVAIRD, Tony; LÖFFLER, Elke. Evaluating the quality of public governance: indicators, models and methodologies. International Review of Administrative Sciences, v. 69, n. 3, p. 3|3-328, 2003.

BRASIL. Lei Complementar n. ${ }^{\circ}$ I0I, de 4 de maio de 2000 (Lei de Responsabilidade Fiscal). Estabelece normas de finanças públicas voltadas para a responsabilidade na gestão fiscal e dá outras providências.

. Lei Complementar n. ${ }^{\circ}|3|$, de 27 de maio de 2009. Acrescenta dispositivos à Lei Complementar no I0I, de 4 de maio de 2000, que estabelece normas de finanças públicas voltadas para a responsabilidade na gestão fiscal e dá outras providências, a fim de determinar a disponibilização, em tempo real, de informações pormenorizadas sobre a execução orçamentária e financeira da União, dos Estados, do Distrito Federal e dos Municípios.

. Lei Complementar ${ }^{\circ} 4.320$, de 17 de março de 1964. Estatui normas gerais de Direito Financeiro para elaboração e controle dos orçamentos e balanços da União, dos Estados, dos Municípios e do Distrito Federal. Diário Oficial da União. Disponível em:<http://www2.senado.gov.br/ sf/legislacao/legisla/>. Acesso em: 25 jul. 2016.

. Lei Complementar $n^{\circ} 8.666$, de 21 de junho de 1993. Regulamenta o art. 37, inciso XXI, da Constituição Federal, institui normas para licitações e contratos da Administração Pública e dá outras providências. Diário Oficial da União. Disponível em: < http:// www.planalto.gov.br/ccivil_03/ leis/L8666cons.htm>. Acesso em: 20 mai. 2016.

- Lei Complementar $n^{\circ}$ 12.527, 18 de novembro de 2011 . Regula $\circ$ acesso a informações previsto no inciso $\mathrm{XXXIII} \mathrm{do} \mathrm{art.}$ $5^{\circ}$, no inciso II do $\S 3^{\circ}$ do art. 37 e no $\S 2^{\circ}$ do art. 216 da Constituição Federal; altera a Lei $n^{\circ} 8.112$, de II de dezembro de 1990; revoga a Lei $\mathrm{n}^{\circ} \mathrm{II}$.III, de 5 de maio de 2005, e dispositivos da Lei $n^{\circ}$ 8.159, de 8 de janeiro de 1991; e dá outras providências. Diário Oficial da União, 18 novembro 20II. Disponível em: <http:// www.planalto.gov.br/ccivil_03/ Ato20II-20I4/20 I I/Lei/LI2527. $\mathrm{htm}>$. Acesso em: 6 fev. 2016.

CAMPOS, Rosana; PAIVA, Denise; GOMES, Suely. Gestão da informação pública: um estudo sobre o Portal Transparência Goiás. Sociedade e Estado, v. 28, n. 2, p. 393-4I7, 2013.

CADBURY COMMITTEE. Report of the committee on the financial aspects of corporate governance. London, 1992. Disponível em: < http://www.ags.gov. au>. Acesso em: 2 fev.20l6.

CFC. CONSELHO FEDERAL DE CONTABILIDADE. NBC TSP Estrutura Conceitual: Estrutura Conceitual para Elaboração e Divulgação de Informação Contábil de Propósito Geral pelas Entidades do Setor Público. Brasília, DF 23 set. 2016.

CONTROLADORIA GERAL DO ESTADO DE GOIÁS. Relatório sobre a Aplicação da Metodologia de Mapeamento de Riscos de Corrupção na Secretaria de Estado do Meio Ambiente e dos Recursos Hídricos, 2012.

FARIA, Jorge et al. As componentes da estrutura organizacional, a cultura de partilha de ideias e a gestão pela qualidade. Jornadas Luso-Espanholas Gestão Científica, p. I-12, 2006.

GOIÁS. Lei n. 18025, de 22 de maio de 20।3. Estabelece que órgãos e entidades da administração estadual devem promover a divulgação de informações públicas de interesse coletivo ou geral independente de solicitação. PALÁCIO DO GOVERNO DO ESTADO DE GOIÁS, em Goiânia, 22 de maio de 2013. Legislação Estadual.

. Lei n. 10460, de 22 de fevereiro de 1988. Estabelece o estatuto dos funcionários públicos civis do estado de goiás e de suas autarquias. PALÁCIO DO GOVERNO DO ESTADO DE GOIÁS, em Goiânia, 22 de fevereiro de 1988. Legislação Estadual 
Decreto n. 7904, de II de junho de 2013. Regulamenta a Lei $\mathrm{n}^{\circ} 18.025$, de 22 maio de 2013 , que dispõe sobre o acesso à informação e a aplicação da Lei $n^{\circ}$ 12.527, de 18 de novembro de 20II, no âmbito do Estado de Goiás, institui o serviço de informação ao cidadão e dá outras providências. PALÁCIO DO GOVERNO DO ESTADO DE GOIÁS, em Goiânia, II de junho de $2013,125^{\circ}$ da República.

Decreto n. 6965 de 2009.

Regulamenta o sítio Goiás Transparente consolidando-se como principal instrumento de promoção da transparência das ações do Poder Executivo do Estado de Goiás. PALÁCIO DO GOVERNO DO ESTADO DE GOIÁS, em Goiânia. Legislação Estadual.

Decreto n. 8356 de janeiro

de 2016 . Estabelece normas complementares de programação e execução orçamentária, financeira e contábil para o exercício de 2016. PALÁCIO DO GOVERNO DO ESTADO DE GOIÁS, em Goiânia, I3 de janeiro de 2016. Legislação Estadual.

Goiás Transparente: portal da transparência em Goiás. Página institucional. 2016. Disponível em: < http://www. transparencia.go.gov.br/pagina. php?id=|44.> Acesso em: 23 fev. 2016.

Tribunal de Contas do Estado. Lei Orgânica do Tribunal de Contas do Estado de Goiás atualizada em fevereiro de 20 I I. Goiás. Disponível em < https://tcenet.tce.go.gov.br/Downloads/Arquivos/001917/Lei\%20 organica\%203.0.pdf>. Acesso em: 10 out. 2016.

HALL, Richard. Organizações: estrutura, processos e resultados. 8 ed. São Paulo: Pearson
Prentice-Hall, 2004.

INSTITUTO BRASILEIRO DE GOVERNANÇA CORPORATIVA. IBGC. Página institucional. Disponível em: < http://www.ibgc. org.br>.Acesso em: 16 mar. 2016. Código das Melhores Práticas de Governança Corporativa. 5 ed. Instituto Brasileiro de Governança Corporativa. São Paulo, SP: IBGC, 2015. Disponível em: <<http://www.ibgc. org.br/Download.aspx?Ref=Codigos $\&$ CodCodigo $=47>$. Acesso em: 07 abr. 2016.

INTERNATIONAL FEDERATION OF ACCOUNTANTS. IFAC. Governance in the Public Sector: A Governing Body Perspective. Study I3, 200 I. Disponível em <http://www.ifac. org>.Acesso em:2I jan.20l6.

IFAC. Página institucio-

nal. Disponível em: <www.ifac. org>. Acesso em: 16 fev. 2016.

IUDÍCIBUS, S. de; MARION, J. C.; PEREIRA, E. Dicionário de Termos de Contabilidade. $2^{\mathrm{a}}$ Ed. São Paulo:Atlas, 2003.

JENSEN, M. C.; MECKLING, William $H$. Theory of the firm: managerial behavior, agency costs and ownership structure. Journal of Financial Economics. V. 3, $n^{\circ}$ 4, 1976.

KISSLER, Leo; HEIDEMANN, Francisco G. Governança pública: novo modelo regulatório para as relações entre Estado, mercado e sociedade? Revista de Administração Pública, v. 40, n. 3, p. 479-499, 2006.

LODI, João Bosco. Governança Corporativa: 0 governo da empresa e o conselho de Administração. $7^{\mathrm{a}}$ reimpressão. Rio de Janeiro: Elsevier, 2000.

LOFT, Anne; HUMPHREY, Christopher; TURLEY, Stuart. In pursuit of global regulation: changing governance and accountability structures at the International Federation of Accountants (IFAC). Accounting, Auditing \& Accountability Journal, v. I9, n. 3, p. 428-45 I, 2006. MARCELLI, Selma. Governança no setor público: diagnóstico das práticas de gestão da Polícia Federal à luz do estudo 13 do PSCIIFAC. 20I3.106 f. Dissertação (Mestrado Executivo em Gestão Empresarial) - Escola Brasileira de Administração Pública e de Empresas, Centro de Formação Acadêmica e Pesquisa, Fundação Getúlio Vargas, Rio de Janeiro.

MATIAS-PEREIRA, José. A governança corporativa aplicada no setor público brasileiro. Administração Pública e Gestão Social, 2, jul. 20 I0. Disponível em: <http://www.apgs.ufv.br/index.php/apgs/article/view/21/22>. Acesso em: 20 fev. 2016.

MELLO, Gilmar Ribeiro de. Governança corporativa no setor público federal brasileiro. 2006. I 9 f. Dissertação de Mestrado. Universidade de São Paulo, São Paulo.

OLIVEIRA, Antônio Gonçalves; PISA, Beatriz Jackiu. IGovP: índice de avaliação da governança pública-instrumento de planejamento do Estado e de controle social pelo cidadão. Revista de Administração Pública, v. 49, n. 5, p. 1263-1290, 2015.

REVISTA BRASILEIRA DE CONTABILIDADE. Sistema Público de Escrituração Digital. Conselho Federal de Contabilidade, RBC, Brasília, ano XXXVII, n. I74. nov./ dez. 2008.

RIBEIRO NETO, Ramon M.; FAMÁ, Rubens. A importância da governança corporativa na gestão das empresas: o caso do grupo 
Orsa. Seminários de Administração da Faculdade de Economia,Administração e Contabilidade da Universidade de São Paulo, v. 6, 2003.

RICHARDSON, Roberto Jarry et al. Pesquisa social: métodos e técnicas. São Paulo:Atlas, 1999.

SALES, Elana C. A. S; PETER, M. G. A.; MACHADO, M.V.V.; NASCIMENTO, C.P.S. Governança no setor público segundo a IFAC: um estudo nas universidades federais brasileiras. In: XXII Congresso Brasileiro de Custos, 2015, Foz do Iguaçu. Anais do Congresso Brasileiro de Custos. PR, Brasil, II a 13 de novembro de 20I5. Disponível em < https:// anaiscbc.emnuvens.com.br/anais/ article/download/3966/3967> Acesso em 13 abr. 2016.

SILVA, Sheila Messias da. Uma análise dos relatórios de gestão do Fundo Nacional de Desenvolvimento da Educação à luz da governança aplicada ao setor público. 2012. 188 f. Dissertação
(Mestrado em Ciências Contábeis) - Centro de Ciências Sociais Aplicadas, Universidade Federal de Pernambuco, Recife-PE.

SILVEIRA, Elen Durán da. Aplicação do conceito de governança corporativa segundo o IFAC em uma empresa pública brasileira. 2013. I43 f. Dissertação (Mestrado em Ciências Contábeis). Programa de Pós Graduação em Contabilidade da Universidade Federal de Santa Catarina, SC.

SLOMSKI, Valmor. Controladoria e Governança na Gestão Pública. São Paulo:Atlas, 2007.

SLOMSKI,Valmor; MELLO, Gilmar Ribeiro de; TAVARES Filho, FrancisCo; MACÊDO,

Fabrício de Queiroz. Governança Corporativa e Governança na Gestão Pública. São Paulo: Atlas, 2008.

TRIBUNAL DE CONTAS DA UNIÃO. Governança Pública: referencial básico de governança aplicável a órgãos e entidades da administração pública e ações indutoras de melhoria/Tribunal de Contas da União. Brasília:TCU, Secretaria de Planejamento, Governança e Gestão, 2014. Dez passos para a boa governança. Brasília: TCU, Secretaria de Planejamento, Governança e Gestão, 20I4. 28 p.

YIN, Robert K. Estudo de Caso: Planejamento e Métodos. Bookman Editora, 200I.

ZONATTO, Vinícius Costa da Silva; FERNANDES, Francisco Carlos; BOGONI, Nadia Mar; ISHIKURA, Edson Ryu. Proposta de um modelo de relatório de administração para o setor público baseado no Parecer de Orientação no 15/87 da Comissão de Valores Mobiliários: um instrumento de governança corporativa para a administração pública. Revista de Administração Pública - Rio de Janeiro, v. 44, n. I, p. I I9-42, 2010. 